\title{
Thermodynamic characterization of phthalocyanine-human serum albumin interaction
}

\author{
Hamid Dezhampanah ${ }^{\mathrm{a}, *}$, Abdol Khalegh Bordbar ${ }^{\mathrm{b}}$ and Shamim Farshad ${ }^{\mathrm{b}}$ \\ ${ }^{a}$ Laboratory of Physical Chemistry, Department of Chemistry, Faculty of Science, University of Guilan, \\ Rasht, Iran \\ ${ }^{\mathrm{b}}$ Laboratory of Biophysical Chemistry, Chemistry Department, University of Isfahan, Isfahan, Iran
}

\begin{abstract}
The thermodynamic of the binding of nickel (II) tetrasulfonated phthalocyanine anion [Ni(tspc $\left.{ }^{4-}\right]$, to human serum albumin (HSA) was investigated in $5 \mathrm{mM}$ aqueous phosphate buffer of $\mathrm{pH} 7.40$ at $25^{\circ} \mathrm{C}$ using optical absorption spectroscopy. The results show that $\left[\mathrm{Ni}(\mathrm{tspc})^{4-}\right]$ does not have any affinity for aggregation due to increasing of salt concentration and exists as monomers even in homogeneous aqueous solutions of high ionic strengths (more than $2 \mathrm{M} \mathrm{NaCl}$ ). The binding constant $(K)$ was obtained by analysis of optical absorption spectra of mentioned complex at various HSA concentrations using SQUAD software. The value of $K$ was estimated to be $4.89 \times 10^{5} \pm 0.03\left(\mathrm{M}^{-1}\right)$ at $25^{\circ} \mathrm{C}$. The thermodynamic parameters were calculated by van't Hoff equation. The enthalpy and entropy changes were $28.08 \mathrm{~kJ} / \mathrm{mol}$ and $203.09 \mathrm{~J} /(\mathrm{mol} \cdot \mathrm{K})$ at $25^{\circ} \mathrm{C}$, respectively. The results indicate that the binding is mainly entropy driven and the enthalpy is unfavorable for it, the hydrophobic forces thus playing a major role in the binding process.
\end{abstract}

Keywords: Human serum albumin, nickel (II) tetrasulfonated phthalocyanine, thermodynamic of binding, optical absorption

\section{Introduction}

Phthalocyanines have been one of the most extensively studied classes of organic functional materials because of their aromatic 18- $\pi$ electron system [8]. They are important blue and green dyes; recently they have been used as photoconducting agents in photocopying machines, as sensing elements in chemical sensors [20,26], electrochromic display devices and photodynamic reagents for cancer therapy and for other medical applications. Microbicides, which serve to prevent the initial entry of the virus into the cell, offer the possibility of protection against transmission of the virus $[11,15]$. There have been a number of previous studies on phthalocyanines and metallophthalocyanines as potential microbicides to kill the human immunodeficiency virus [27], the vesicular stomatitis virus [19], bovine viral diarrhea virus [2], pseudorabies virus [2] and herpes simplex virus [25]. All of these studies involve photoactivation of the phthalocyanine to produce species (singlet oxygen or free radical) that kill the virus. Conjugation of sensitizer with biological targeting agents, e.g., monoclonal antibodies or lipoproteins, increases the

\footnotetext{
${ }^{*}$ Corresponding author: Hamid Dezhampanah, Laboratory of Physical Chemistry, Department of Chemistry, Faculty of Science, University of Guilan, P.O. Box 41335-1914, Rashat 0098, Iran. Tel.: +98 131 32436305; Fax: +98 131 3233262; E-mails: h.dpanah@guilan.ac.ir,h_dpanah@yahoo.com.
} 


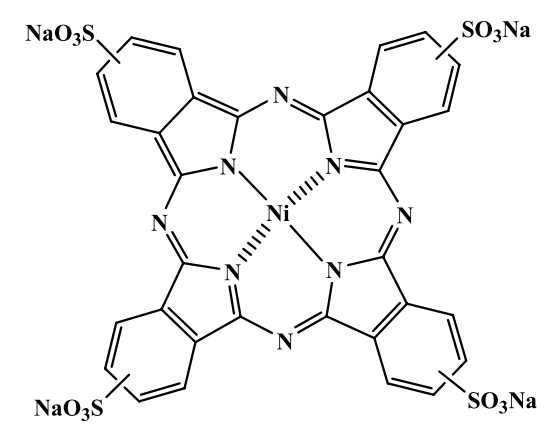

Fig. 1. Chemical structures of $\mathrm{Ni}(\mathrm{tspc})^{4}$.

concentration of sensitizer on targeted tissue over normal tissue, providing additional level of selectivity and possibility to reduce effective sensitizer concentration, and thus phototoxicity to normal tissue $[16,22]$. To have a full understanding of the modes of drug actions, their interaction with all possible biological targets, including nucleic acids, enzymes and other proteins, is required [5,9].

Phthalocyanines taken into the blood circulation system as tumor localizing photosensitizers for PDT are transported to target tissues by human serum albumin (HSA) and other plasma proteins such as low- and high-density lipoproteins. HSA is the most abundant plasma protein, which plays key roles in transport, distribution and metabolism of many endogenous and exogenous ligands, such as fatty acids, metabolites and drugs [21]. The binding to HSA often changes the photophysical and photochemical properties of phthalocyanines [10], as a consequence of the interaction with the specific amino acids near the binding site. It is accepted that there are two major specific drug binding sites, site I and site II, in HSA, which are located in subdomain IIA and IIIA [14], respectively. Therefore, the understanding of the interaction of phthalocyanines with HSA is of utmost importance in formulating safe drugs and effective dosages. A wide variety of techniques have been exploited to investigate the binding behavior of ligand to protein, including UV-Vis [6,7,17], fluorescence [4,6,7,12,24,32], infrared (IR) [12,32] and circular dichroism (CD) spectroscopies [6,12,32], as well as capillary electrophoresis [31], ${ }^{1} \mathrm{H}$ NMR spectroscopy [29] and molecular modeling [12,32].

We have previously reported the spectroscopic studies to characterize the interactions of some drugs with serum albumin [1,3]. In this study to elucidate the binding behavior of nickel (II) tetrasulfonated phthalocyanine anion $\mathrm{Ni}(\mathrm{tspc})^{4-}$ (Fig. 1) with HSA at various temperatures using UV-Vis absorption spectroscopic technique. The binding constants were determined by analyzing optical absorption spectra of complex at various HSA concentrations using SQUAD software [30]. In particular, we determined the standard free energy $\Delta G^{o}$, enthalpy $\Delta H^{o}$ and entropy $\Delta S^{o}$ for the binding of mentioned complex to HSA. Comparison of thermodynamic data leads us to understand the mechanism of interaction.

\section{Material and methods}

\subsection{Chemicals and preparations}

HSA (free fatty acid, fraction V) and nickel (II) phthalocyanine-tetrasulfonic acid tetra sodium salt were obtained from Sigma Chemical Co. and used as received. All other chemical reagents were purchased from Merck and Aldrich Companies. All experiments were carried out in doubled distilled water 
in $5 \mathrm{mM}$ phosphate buffer, $\mathrm{pH}$ 7.40. The probe concentration of HSA was determined spectrophotometrically considering the molar extinction coefficient of $\varepsilon_{280 \mathrm{~nm}}=4.2 \times 10^{3} \mathrm{M}^{-1} \mathrm{~cm}^{-1}$. In all experiments, the HSA solutions were freshly prepared before spectral analysis and the $\mathrm{Ni}(\mathrm{tspc})^{4-}$ solutions were protected from direct sunlight and fluorescent light until they were inserted into the cell compartment. The $\mathrm{pH}$ was measured at $25.0^{\circ} \mathrm{C}$ with a Metrohm F-12 and the adjustment to the desired $\mathrm{pH}$ value accomplished by the addition of $\mathrm{HCl}$ or $\mathrm{NaOH}$.

\subsection{Optical absorption}

Spectrophotometric measurements were carried out using a UV-Vis double beam spectrophotometer Shimadzo model Uv-2101pc equipped with a thermostat, which controls the temperature of the cell compartment with precision of $\pm 0.1^{\circ} \mathrm{C}$.

In typical titration experiments, $2.0 \mathrm{ml}$ solutions of $\mathrm{Ni}(\mathrm{tspc})^{4-}\left(2.91 \times 10^{-5} \mathrm{M}\right)$, was titrated with HSA solution $\left(4.60 \times 10^{-4} \mathrm{M}\right)$. UV-Vis spectra were recorded in the range of $250-800 \mathrm{~nm}$ about 5 min after each addition $(10 \mu \mathrm{l})$ of protein solution. It has been checked that this maintenance time is enough to reach the equilibrium of the $\mathrm{HSA}-\mathrm{Ni}(\mathrm{tspc})^{4-}$ reaction. 50 wavelengths showing suitable absorbance variations upon addition of HSA were selected and the equilibrium constants were calculated by using the SQUAD program. This program is designed to calculate the best values for the stability constants of the proposed equilibrium model by employing a non-linear least squares approach. The program is completely general in scope, having the capability to refine stability constants for the general complex $M_{m} M_{l}^{\prime} H_{J} L_{n} L_{q}^{\prime}$, where $m, l, n, q \geqslant 0$ and $J$ is positive (for protons), negative (for hydroxyl ions) or zero. The algorithm employed in SQUAD has been previously described [18,30]. We used this program to evaluate the HSA-Ni(tspc) ${ }^{4-}$ equilibrium. Our input data consist of (a) the absorbance values $A_{i, k}$, for each spectrum, giving a total of I for each wavelength, and a grand total of NW; (b) the total HSA and $\mathrm{Ni}$ (tspc) $)^{4-}$ concentrations, $C_{B_{i}}, C_{P_{i}}$, and path length $b_{i}$, for each spectrum; (c) the known molar absorptivity of free $\mathrm{Ni}(\mathrm{tspc})^{4-}$. The program uses Gauss-Newton non-linear least-squares algorithm for minimizing the sum of residuals, $U$, which is calculated from Eq. (1):

$$
U_{\mathrm{obs}}=\sum_{i=1}^{15} \sum_{k=1}^{50}\left(A_{i, k}^{\mathrm{cal}}-A_{i, k}^{\mathrm{obs}}\right)^{2},
$$

where $A_{i, k}^{\text {obs }}$ is the observed absorbance value of the $i$ th solution at $k$ th wavelength, given a total of 15 solutions and a grand total of 50 wavelengths.

The output data are the equilibrium formation constant, $K_{i j}$ of $B_{i} P_{j}$ complex, where $B$ and $P$ represent HSA and $\mathrm{Ni}(\mathrm{tspc})^{4-}$, respectively. $K_{i j}$ is defined with respect to Eq. (3):

$$
\begin{gathered}
i B+j P \leftrightarrow B_{i} P_{j}, \\
K_{i j}=\frac{\left[B_{i} P_{j}\right]}{[B]^{i}[P]^{j}} .
\end{gathered}
$$

The values of $U$, representing percent error represent of uncertainly for $K_{i j}$, are also calculated by the program. 


\section{Results and discussion}

\subsection{Solution properties of $\mathrm{Ni}(t s p c)^{4-}$}

Optical absorption spectrum of $\mathrm{Ni}(\mathrm{tspc})^{4-}$ shows two major electronic absorption bands, namely the B (or soret) band at approximately $340 \mathrm{~nm}$ in ultraviolet and Q band between 600 and $700 \mathrm{~nm}$ (visible). As an extensively conjugated aromatic chromophore the electronic transitions have $\pi \rightarrow \pi^{*}$ character. The molar extinction coefficient of the Q-band of the $\mathrm{Ni}(\mathrm{tspc})^{4-}$ in our experimental conditions was $3.14 \times 10^{4} \mathrm{~cm}^{-1} \mathrm{M}^{-1}$ at $25^{\circ} \mathrm{C}$. The Q-band absorption obeys Beer's law over an extended concentration range to $10^{-4} \mathrm{M}$ in phosphate buffer $5 \mathrm{mM}, \mathrm{pH}=7.40$ at $25^{\circ} \mathrm{C}$. From this observation we can conclude that this phthalocyanine dose not aggregate in the experimental concentration range.

\subsection{Effect of inorganic salts}

The effect of $\mathrm{NaCl}$ on the absorption spectrum of $\mathrm{Ni}(\mathrm{tspc})^{4-}$ is shown in Fig. 2. As the concentration of $\mathrm{NaCl}$ increases, the absorbance at all of the spectral regions of the studied phthalocyanine significantly decreases. The addition of sodium chloride does not induce significant changes in the spectral feature of the B-band, while hypochromicity with blue shift (about $15 \mathrm{~nm}$ ) was observed in Q-band region. The decrease in the absorbance for Ni(tspc $)^{4-}$ spectra is accompanied with blue shift of Q-band which represent the formation of well-defined aggregates. These results also represent the strong electrolyte effect on aggregation state of $\mathrm{Ni}(\mathrm{tspc})^{4-}$.

\subsection{Binding of $\mathrm{Ni}(\mathrm{tspc})^{4-}$ to HSA. Optical absorption}

Figure 3 shows the absorption spectra of $\mathrm{Ni}(\mathrm{tspc})^{4-}$ in the presence of HSA of varying concentrations at $\mathrm{pH}$ 7.40. In $5 \mathrm{mM}$ phosphate buffer, $\mathrm{Ni}(\mathrm{tspc})^{4-}$ exists in the anionic form, $\mathrm{Ni}(\mathrm{tspc})^{4-}$ and its Q-band appears at $624 \mathrm{~nm}$ in the absence of HSA. Upon gradual addition of HSA, a new peak centered at $674 \mathrm{~nm}$ appeared at the expense of the original peak at $624 \mathrm{~nm}$ with accompanying isosbestic

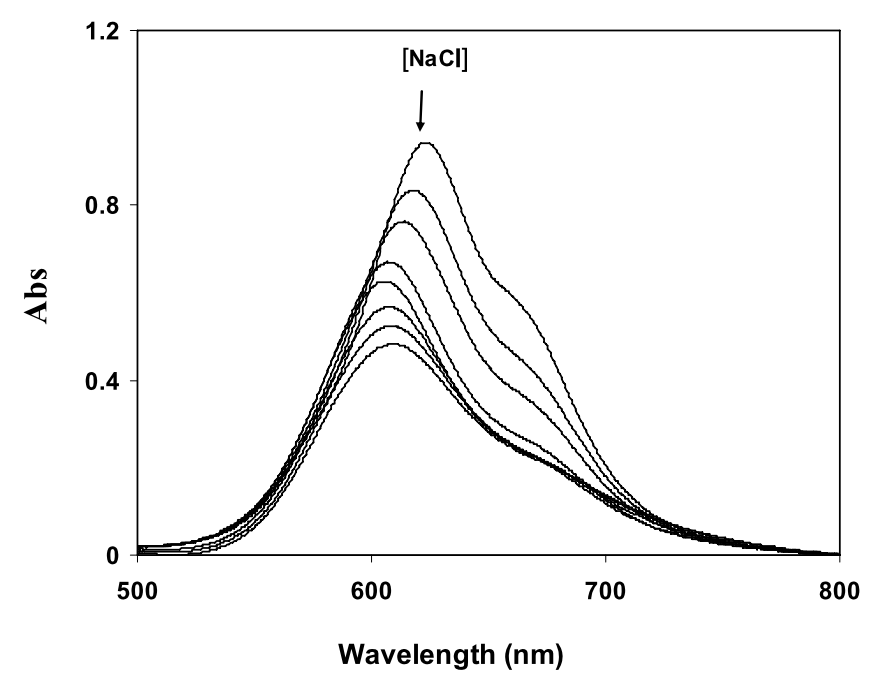

Fig. 2. Absorption spectral changes of $\mathrm{Ni}(\mathrm{tspc})^{4-}$ complex upon addition of $\mathrm{NaCl}(0,0.05,0.14,0.52,0.93,1.30,1.86$ and $2.64 \mathrm{M})$ in water $(\mathrm{pH} 7.40)$ at $25^{\circ} \mathrm{C}$. The arrow shows the increasing of $\mathrm{NaCl}$ concentration. 


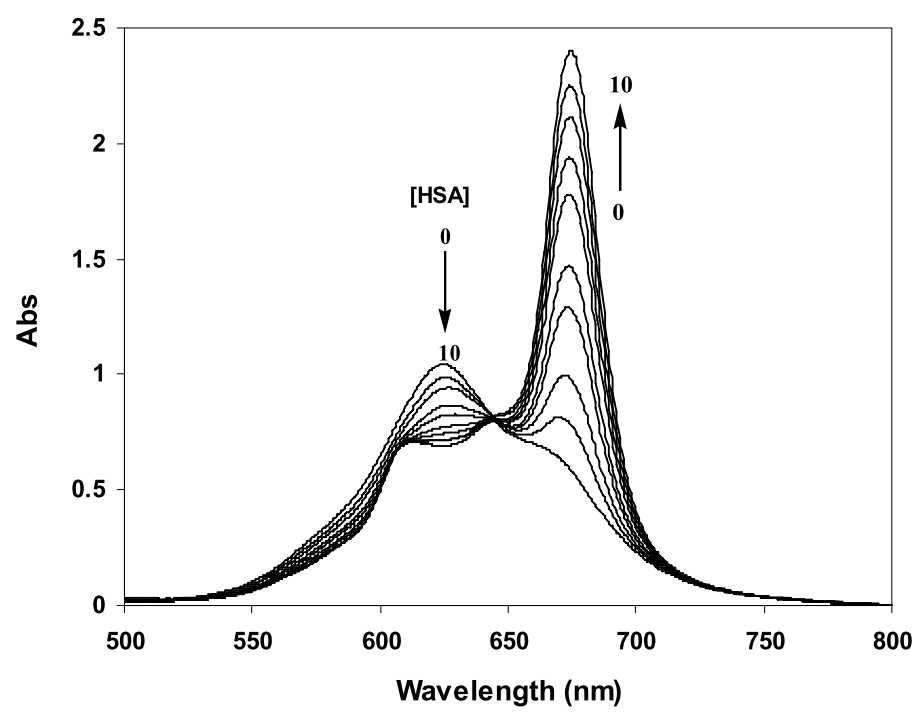

Fig. 3. UV-Vis spectra of $\mathrm{Ni}(\mathrm{tspc})^{4-}\left(2.91 \times 10^{-5} \mathrm{M}\right)$ in the presence of HSA at pH 7.40 [HSA]: (1) 0 , (2) $3.15 \times 10^{-5}$, (3) $5.88 \times 10^{-5}$, (4) $6.97 \times 10^{-5}$, (5) $8.05 \times 10^{-5}$, (6) $9.08 \times 10^{-5}$, (7) $9.38 \times 10^{-5}$, (8) $9.59 \times 10^{-5}$, (9) $9.75 \times 10^{-5}$, (10) $9.98 \times 10^{-5} \mathrm{M}$.

point at $642 \mathrm{~nm}$, confirming the stoichiometric formation of the complex between HSA and phthalocyanine [28]. The B-band at $340 \mathrm{~nm}$ was increased in intensity. Similar situations were observed at all the studied temperatures and the positions of Q- and B-bands and isosbestic points do not show significant differences on changing the temperature. The isosbestic point and hypochromicity without any shift in B-band were observed, which represents the existence of interaction between HSA and phthalocyanine complex. The appearance of isosbestic point in phthalocyanine spectra clearly indicates the existence of simple equilibrium between free phthalocyanine and 1:1 phthalocyanine-HSA complex (Eq. (4)):

$$
\text { phthalocyanine }+\mathrm{HSA} \rightleftarrows \text { phthalocyanine }- \text { HSA. }
$$

The above equilibrium can be monitored up to [HSA]/[phthalocyanine] molar ratio equal to 2 . The variation of absorption in the Q-band versus [HSA]/[phthalocyanine] was shown in Fig. 4. This shows the usual feature of saturation binding process. This situation was observed in all studied temperatures.

\subsection{Thermodynamics of HSA-phthalocyanine binding process}

The binding studies were carried out at 293, 298, 308 and $313 \mathrm{~K}$. At these temperatures, HSA does not undergo any structural degradation. The binding constant at any specified temperature was determined by the concentration dependence of UV-Vis absorption data, using SQUAD program. The absorption data were analyzed by assuming 1:1 or $2: 1$ and/or simultaneous 1:1 and 2:1 molar ratios of phthalocyanine to HSA. Fitting of the experimental data (15 points), to the proposed stoichiometric models was evaluated by the sum of squares of the calculated points by the model. The results show that the best fitting corresponds to the 1:1 complex model at studied temperatures with the residual sum of squares, U; ranging between 1024 and 1023. The calculated binding constants are given in Table 1. As can be seen in this table, the binding constants increase with increasing the temperatures. It can be described as increasing of complex stability results in higher values of the binding constants. The acting forces between 


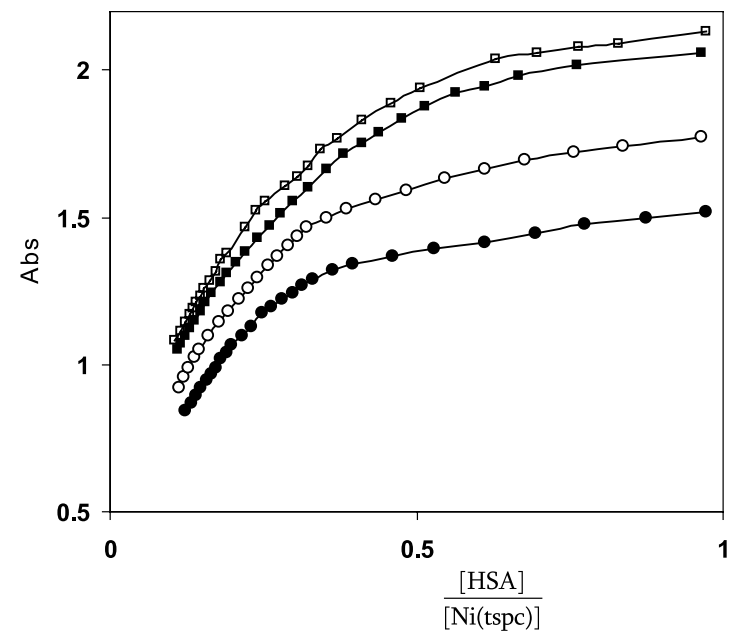

Fig. 4. The variations of max absorption in various molar ratio of $[\mathrm{HSA}] /\left[\mathrm{Ni}(\mathrm{tspc})^{4-}\right]$ at $624 \mathrm{~nm}, 5 \mathrm{mM}$ phosphate buffer, $\mathrm{pH} 7.40$ and the temperature $20^{\circ} \mathrm{C}(\mathbf{\bullet}), 25^{\circ} \mathrm{C}(\mathrm{O}), 35^{\circ} \mathrm{C}(\boldsymbol{\square}), 40^{\circ} \mathrm{C}(\square)$, respectively.

Table 1

Thermodynamic parameters and affinity constants for binding of $\mathrm{Ni}(\mathrm{tspc})^{4-}$ to HSA at $5 \mathrm{mM}$ phosphate buffer $\mathrm{pH} 7.40$ and various temperatures

\begin{tabular}{lcccc}
\hline$T(\mathrm{~K})$ & $(K \pm \Delta K) \times 10^{5}\left(\mathrm{M}^{-1}\right)$ & $\Delta G^{o}(\mathrm{~kJ} / \mathrm{mol})$ & $\Delta H^{o}(\mathrm{~kJ} / \mathrm{mol})$ & $\Delta S^{o}(\mathrm{~J} /(\mathrm{mol} \cdot \mathrm{K})$ \\
\hline 293.15 & $4.08 \pm 0.04$ & $-31.49 \pm 0.28$ & $28.08 \pm 3.28$ & $203.21 \pm 5.28$ \\
298.15 & $4.89 \pm 0.03$ & $-32.47 \pm 0.34$ & $28.08 \pm 3.28$ & $203.09 \pm 6.25$ \\
308.15 & $7.37 \pm 0.04$ & $-34.61 \pm 0.36$ & $28.08 \pm 3.28$ & $203.43 \pm 4.65$ \\
313.15 & $8.22 \pm 0.03$ & $-35.53 \pm 0.30$ & $28.08 \pm 3.28$ & $203.13 \pm 3.78$ \\
\hline
\end{tabular}

a small molecule and macromolecule include hydrogen bond, van der Waals force, electrostatic force, hydrophobic interaction force and so on. The energetic of protein-ligand equilibria can be conveniently characterized by three thermodynamic parameters; the standard Gibbs free energy, $\Delta G^{o}$, the standard molar enthalpy, $\Delta H^{o}$ and the standard molar entropy, $\Delta S^{o} . \Delta G^{o}$ can be calculated from the equilibrium constant, $K$, of the reaction using the familiar relationship, $\Delta G^{o}=-R T \ln K$ in which $R$ and $T$ are gas constant and the absolute temperature, respectively. If heat capacity change for the reaction, $\Delta C_{p}^{o}$, is essentially zero, the van't Hoff equation (Eq. (5)) gives a linear plot of $\ln K$ versus $\frac{1}{T}$ :

$$
\partial \ln K=-\left(\Delta H^{o} / R\right) \partial\left(\frac{1}{T}\right)
$$

The standard enthalpy can be calculated from the slope of the straight line, $-\frac{\Delta H^{o}}{R}$ and the standard entropy by the following equation (Eq. (6)):

$$
\Delta S^{o}=\left(\Delta H^{o}-\Delta G^{o}\right) / T \text {. }
$$

Since, like most of other reactions involving biological macromolecules, for our system activity coefficients are not known, the usual procedure is to assume a value of unity and to use equilibrium concentrations instead of activities. Therefore, the value of $K$ may vary with composition. Since protein-ligand 


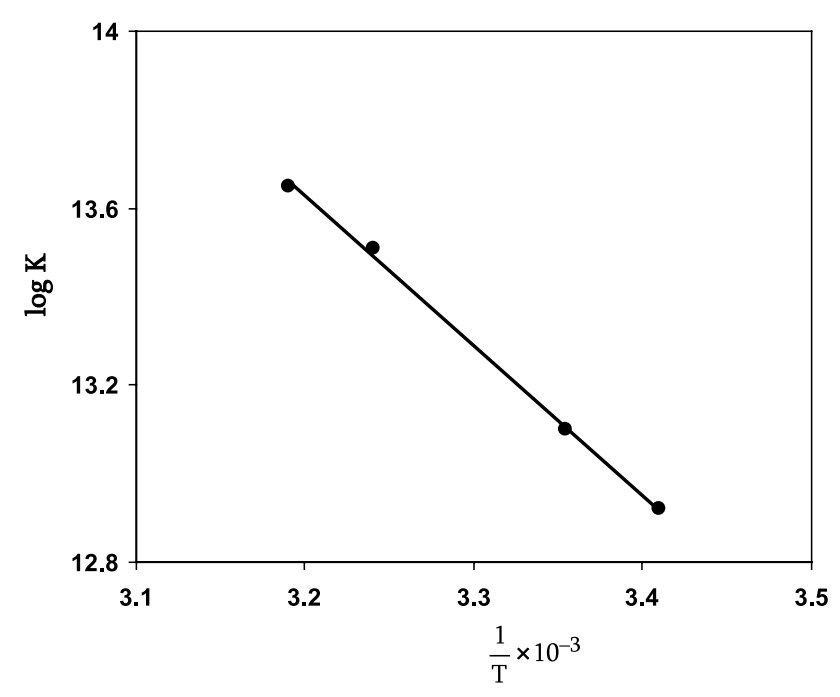

Fig. 5. The van't Hoff plot of HSA-binding of Ni(tspc $)^{4-}$.

equilibrium often depend on many factors such as $\mathrm{pH}$, buffering compounds, salts, reducing agents, etc. and their influence on $K$ is seldom known, it appears appropriate to adopt the terminology of apparent equilibrium constants, $K^{\prime}$, Gibbs energy, $\Delta G^{o^{\prime}}$, enthalpy, $\Delta H^{o^{\prime}}$ and entropy, $\Delta S^{o^{\prime}}$.

The van't Hoff plots for binding of this phthalocyanine complex to HSA in phosphate buffer is shown in Fig. 5 and their calculated thermodynamic parameter is reported in Table 1. Ross and Subramanyam [23] have characterized the sign and magnitude of the thermodynamic parameter associated with various individual kinds of interaction that may take place in protein association processes. From the point of view of water structure, a positive $\Delta S^{o^{\prime}}$ value is frequently taken as evidence for hydrophobic interaction. The negative value of $\Delta G^{o^{\prime}}$ reveals that the interaction process is spontaneous. The positive $\Delta H^{o^{\prime}}$ and $\Delta S^{o^{\prime}}$ values of the interaction of $\mathrm{Ni}(\mathrm{tspc})^{4-}$ and HSA indicate that the binding is mainly entropy driven and the enthalpy is unfavorable for it, the hydrophobic forces thus playing a major role in the binding $[13,23]$.

\section{Conclusion}

The affinity of serum albumin for this phthalocyanine indicates the role of this protein as endogenous carriers of this phthalocyanine as DNA binders. With respect to our results, the stoichiometry of HSAphthalocyanine binding is 1:1. The measured binding constants suggest a relatively high affinity of HSA for binding to this phthalocyanine.

However, as a drug carrier, HSA may aid in the selective delivery of phthalocyanine to a tumor region and facilitate drug access into the cell through receptor mechanisms. It is believed that the affinity of HSA for these complexes might be sufficiently high in order to make HSA a carrier at all, but not too high in order to allow drug release at the target.

With respect to thermodynamics of phthalocyanine-HSA binding, we have found that phthalocyanine-HSA association is entropy driven like porphyrin-HSA association, as expected for hydrophobic interactions. Such interactions are, then, substantial (although not single) contributors to the affinity of phthalocyanine for HSA. 


\section{Acknowledgements}

We are grateful to the Research Councils of Guilan and Isfahan Universities for their financial support.

\section{References}

[1] M. Asadi, A.K. Bordbar, E. Safaei and J. Ghasemi, Journal of Molecular Structure 70 (2004), 41-47.

[2] E. Ben-Hur, W.S. Chan, Z. Yim, M.M. Zuk, V. Dayal, N. Roth et al., Developments in Biological Standardization 102 (2000), 149-155.

[3] A.K. Bordbar, H. Dezhampanah, M. Asadi, E. Safaei, N. Sohrabi and Y. Khodadost, Journal Porphyrin Phthalocyanines 11 (2007), 555-560.

[4] I.E. Borissevitch, T.T. Tominaga, H. Imasato and M. Tabak, Analytica Chimica Acta 343 (1997), 281-286.

[5] D. Charbonneau, M. Beauregard and H.A. Tajmir-Riahi, Journal of Physical Chemistry B 113(1) (2009), 1777-1784.

[6] S. Chatterjee and T.S. Srivastava, Journal of Porphyrins and Phthalocyanines 4 (2000), 147-157.

[7] S. Cohen and R. Margalit, Biochemical Journal 270 (1990), 325-330.

[8] A.A. Esenpinar and M. Bulut, Dyes and Pigments 76 (2008), 231-235.

[9] E. Froehlich, J.S. Mandeville, C.J. Jennings, R. Sedaghat-Herati and H.A. Tajmir-Riahi, Journal of Physical Chemistry B 113 (2009), 6986-6993.

[10] R. Galántai, I.B. Nagy, K. Mó dos, J. Kardos, P. Závodszky and J. Fidy, Archives of Biochemistry and Biophysics 373 (2000), 261-270.

[11] T.M. Hammett, T.H. Mason, C.L. Joanis, S.E. Foster, P. Harmon, R.R. Robles et al., Sexually Transmitted Diseases 27 (2000), 119-126.

[12] W.Y. He, Y. Li, H.Z. Si, Y.M. Dong, F.L. Sheng, X.J. Yao et al., Journal of Photochemistry and Photobiology A: Chemistry 182 (2006), 158-167.

[13] Y.J. Hu, Y. Liu, J.B. Wang, X.H. Xiao and S.S. Qu, Journal of Pharmaceutical and Biomedical Analysis 36 (2004), 915-919.

[14] Y.V. Il'ichev, J.L. Perry and J.D. Simon, Journal of Physical Chemistry B 106 (2002), 452-459.

[15] C.E. Isaacs, R. Pullarka and R. Kascsak, Advances in Experimental Medicine and Biology 501 (2001), $223-232$.

[16] Y.N. Konan, R. Gurny and E. Allemann, Journal of Photochemistry and Photobiology B: Biology 66 (2002), 89-106.

[17] P. Kubat, K. Lang and P. Anzenbacher, Biochimica et Biophysica Acta 1670 (2004), 40-48.

[18] D.J. Leggett and W.A.E. McBryde, Analytical Chemistry 47 (1975), 1065-1070.

[19] A.C.E. Moor, A.E. Wagenaars-van Gompel, R.C.A. Hermanns, J. Meulen, J. Smit, J. Wilschut et al., Journal of Photochemistry and Photobiology A: Chemistry 69 (1999), 353-359.

[20] M. Özer, A. Altindal, A.R. Özkaya, M. Bulut and Ö. Bekaroglu, Synthetic Metals 155 (2005), 222-231.

[21] I. Petitpas, A.A. Bhattacharya, S. Twine, M. East and S. Curry, Journal of Biological Chemistry 276 (2001), $22804-22809$.

[22] E. Reddi, Journal of Photochemistry and Photobiology B: Biology 37 (1997), 189-195.

[23] D.P. Ross and S. Subramanian, Biochemistry 20 (1981), 3096-3099.

[24] M. Rotenberg and R. Margalit, Biochemical Journal 229 (1985), 197-203.

[25] S. Rywkin, E. Ben-Hur, Z. Malik, A.M. Prince, Y.S. Li, M.E. Kenney et al., Journal of Photochemistry and Photobiology A: Chemistry 60 (1994), 165-170.

[26] Ü. Salan, A. Altındal, M. Bulut and Ö. Bekaroglu, Tetrahedron Letters 46 (2005), 6057-6061.

[27] A.N. Vaorov, L.G. Marzilli, R.W. Compans and D.W. Dixon, Antiviral Research 59 (2003), 99-109.

[28] Y.J. Wei, K.A. Li and S.Y. Tong, Analytica Chimica Acta 341 (1997), 97-104.

[29] V.E. Yushmanov, T.T. Tominaga, I.E. Borissevitch, H. Imasato and M. Tabak, Magnetic Resonance Imaging 14 (1996), 255-261.

[30] L. Zekan, I. Nagypal and D.J. Leggett, A comprehensive program for the evaluation of potentiometric and/or spectrophotometric equilibrium data using analytical derivatives, in: Computational Methods, PSEQUAD, eds, Plenum Press, New York, USA, 1991.

[31] W.B. Zhang, L.H. Zhang, G.C. Ping, Y.K. Zhang and A. Kettrup, Journal of Chromatography B 768 (2002), 211-214.

[32] Y.H. Zhang, Y. Li, L.J. Dong, J.Z. Li, W.Y. He, X.G. Chen et al., Journal of Molecular Structure 875 (2008), 1-8. 


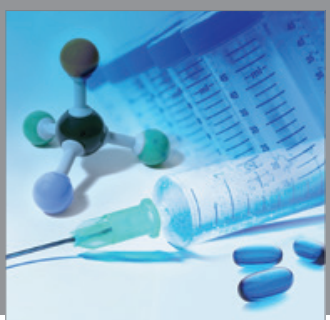

International Journal of

Medicinal Chemistry

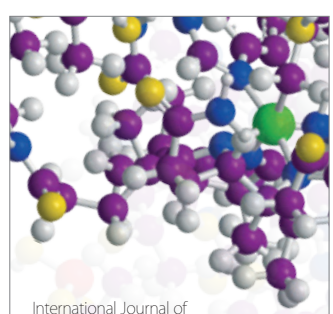

Carbohydrate Chemistry

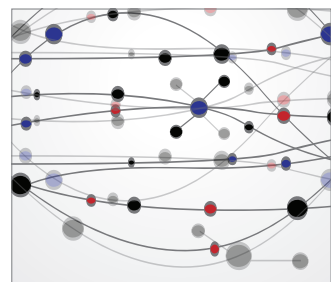

The Scientific World Journal
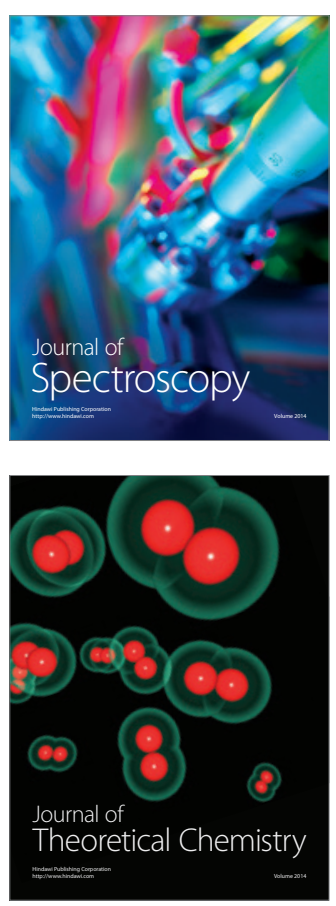
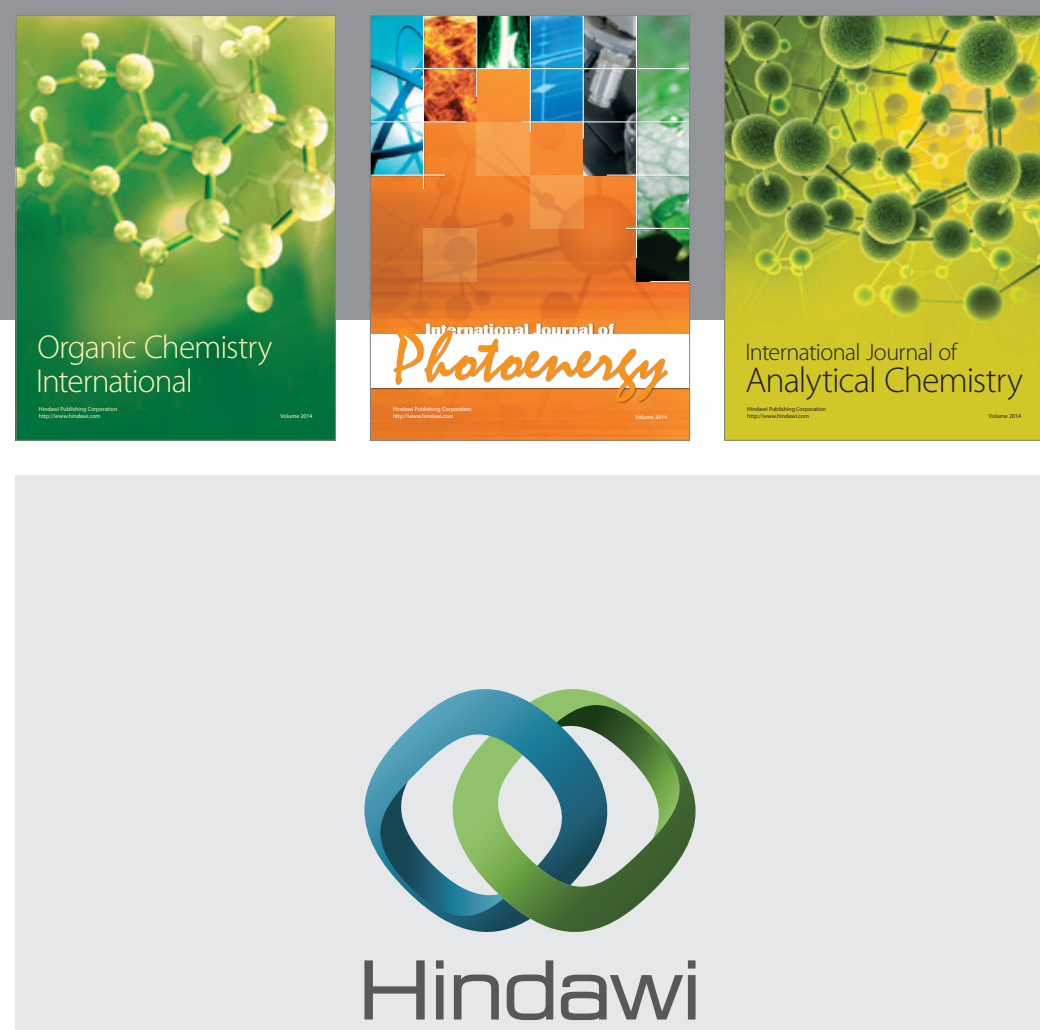

Submit your manuscripts at

http://www.hindawi.com
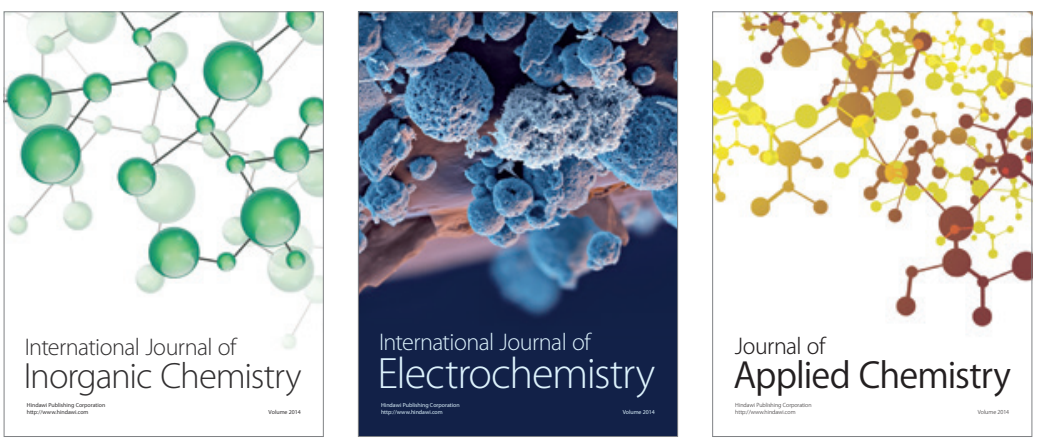

Journal of

Applied Chemistry
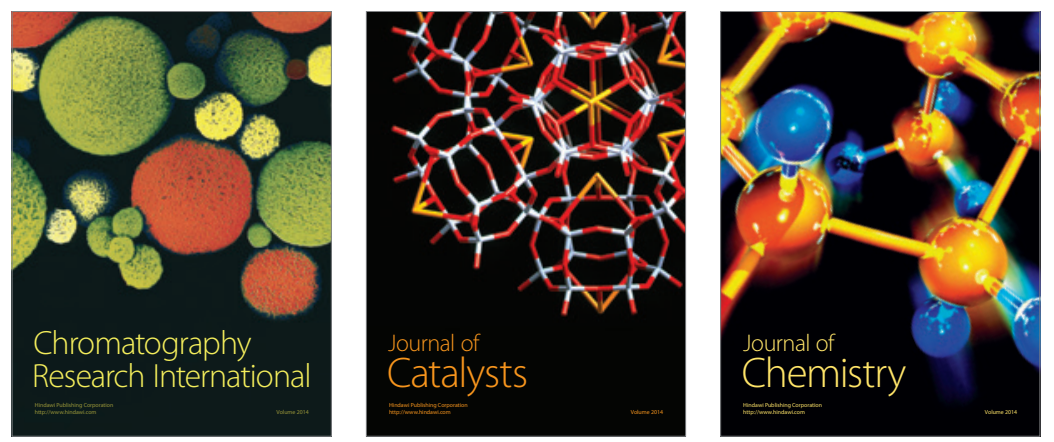
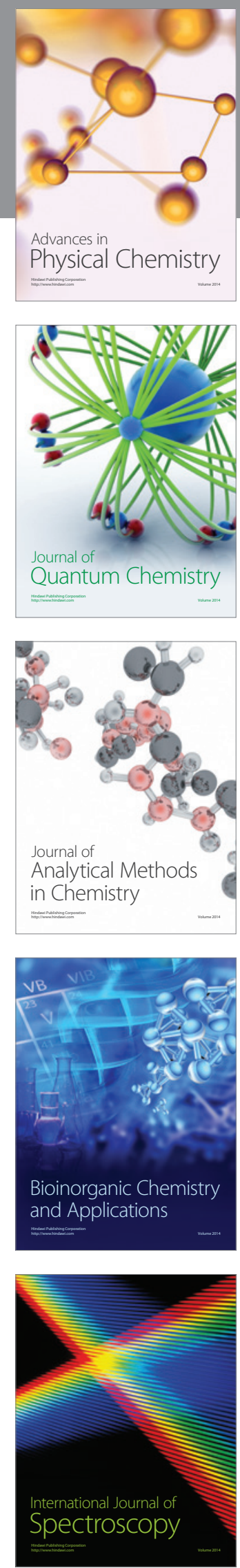